\title{
Impact of Intravenous Naltrexone on Intravenous Morphine-Induced High, Drug Liking, and Euphoric Effects in Experienced, Nondependent Male Opioid Users
}

\author{
Lynn R. Webster, ${ }^{1}$ Franklin K. Johnson, ${ }^{2}$ Joseph Stauffer, ${ }^{2,3}$ Beatrice Setnik ${ }^{2}$ and Sabrina Ciric ${ }^{4}$ \\ 1 Lifetree Clinical Research, Salt Lake City, UT, USA \\ 2 Alpharma Pharmaceuticals LLC, a wholly owned subsidiary of King Pharmaceuticals Inc., Bridgewater, \\ NJ, USA, acquired by Pfizer Inc. in March 2011 \\ 3 Johns Hopkins University School of Medicine, Baltimore, MD, USA \\ 4 Celerion, Montreal, QC, Canada
}

\section{Abstract}

Background: Opioid analgesics can be abused by crushing followed by solubilization and intravenous injection to attain rapid absorption. Morphine sulfate and naltrexone hydrochloride extended release capsules $\left(\mathrm{EMBEDA}^{\circledR}\right.$, MS-sNT), indicated for management of chronic, moderate to severe pain, contain pellets of morphine sulfate with a sequestered naltrexone core. Should product tampering by crushing occur, the sequestered naltrexone is intended for release to reduce morphine-induced subjective effects.

Objective: This study compared self-reports of high, euphoria, and drugliking effects of intravenous morphine alone versus intravenous morphine combined with naltrexone in a clinical simulation of intravenous abuse of crushed MS-sNT.

Methods: This single-center, randomized, double-blind, crossover study characterized subjective effects of naltrexone administered intravenously at the same ratio to morphine present in MS-sNT. Subjects were male and had used prescription opioids five or more times within the previous 12 months to get 'high' but were not physically dependent on opioids. The primary outcome was the response to the Drug Effects Questionnaire (DEQ) question \#5, "How high are you now?" (100 mm Visual Analog Scale [VAS]). The secondary outcome was the response to a Cole/Addiction Research Center Inventory (ARCI) Stimulation-Euphoria modified scale. Additional outcomes included response to VAS drug liking, the remaining DEQ questions, and pupillometry. Results: Administration of intravenous naltrexone following intravenous morphine diminished mean high (29.8 vs $85.2 \mathrm{~mm})$, Cole/ARCI StimulationEuphoria (13.7 vs $27.8 \mathrm{~mm}$ ), and drug-liking (38.9 vs $81.4 \mathrm{~mm}$ ) scores (all 
$\mathrm{p}<0.0001)$ compared with intravenous morphine alone. No serious adverse events occurred as a result of the tested ratio of naltrexone to morphine.

Conclusions: Results in this study population suggest that naltrexone added to morphine in the $4 \%$ ratio within MS-sNT mitigates the high, euphoria, and drug liking of morphine alone, potentially reducing the attractiveness for product tampering. Assessment of the true clinical significance of these findings will require further study.

\section{Introduction}

Opioid analgesics are an important component of comprehensive management plans for chronic pain in appropriately selected and monitored patients. Extended-release opioid formulations have enabled patients to attain around-the-clock pain relief with less frequent dosing than with immediate-release products; however, they are vulnerable to tampering by abusers wishing to gain access to the larger supply of opioid within each dose unit..$^{[1,2]}$ For example, some prescription opioids can be abused by injection of solubilized crushed product to achieve the rapid absorption and high opioid plasma levels associated with a 'rush' or 'high.'[2]

Abuse of prescription drugs, including opioid analgesics, has increased substantially since the mid-1990s, ${ }^{[3-8]}$ creating a need for products that are a less inviting target for abuse. ${ }^{[9-13]}$ Among US Department of Health and Human Services, FDA, Center for Drug Evaluation and Research recommendations is the call for drug manufacturers to "modify opioid painkillers so that they are more difficult to tamper with and/or combine them with agents that block the effect of the opioid if it is dissolved and injected."[14-16] Naltrexone hydrochloride is an orally available opioid antagonist that competitively binds to $\mu$-opioid receptors and reduces the euphoric effects of $\mu$-opioid agonists, such as morphine. ${ }^{[17]}$ Naltrexone, administered generally at doses of $50-100 \mathrm{mg} /$ day for oral administration or $380 \mathrm{mg} / \mathrm{month}$ for intramuscular administration, is used as an adjunctive treatment of alcoholism and for blockade of the effects of opioids. ${ }^{[18,19]}$ Naltrexone is also present in a much smaller amount as a sequestered component in the individual pellets in morphine sulfate and naltrexone hydrochloride extended release capsules (EMBEDA ${ }^{\circledR}$, MS-sNT, formerly ALO-01). MS-sNT is indicated for the management of chronic, moderate to severe pain. ${ }^{[20]}$ The ratio of morphine sulfate to naltrexone hydrochloride in MS-sNT is $100: 4 .^{[20]}$ Thus, a $30 \mathrm{mg}$ capsule of MS-sNT contains $30 \mathrm{mg}$ of morphine sulfate and $1.2 \mathrm{mg}$ of sequestered naltrexone, an amount much lower than the aforementioned clinical doses of naltrexone.

The sequestered core of naltrexone in MS-sNT is intended for release only upon product tampering (crushing) to reduce morphine-induced subjective effects. ${ }^{[20]}$ Previous pharmacokinetic studies had demonstrated that when pellets from MS-sNT were crushed and taken orally, both the morphine and the naltrexone were fully bioavailable when compared with the equivalent amount of morphine and naltrexone in solution. ${ }^{[21,22]}$ Results of an oral abuse liability study in 32 recreational drug users indicated that MS-sNT capsules, taken orally either whole or with liquid after the pellets were crushed, were significantly less desirable than morphine sulfate solution, as evaluated using several subjective measures including Cole/Addiction Research Center Inventory (ARCI) Stimulation-Euphoria, ${ }^{[23]}$ drug liking, and subjective monetary value of drug. ${ }^{[21]}$ Overall, $87.5 \%$ of subjects in the oral study experienced some degree of reduced drug liking after receiving the crushed MS-sNT compared with morphine sulfate solution. ${ }^{[20]}$

The purpose of the study presented here was to assess the abuse liability of MS-sNT if the product were abused intravenously. Since the excipients in the crushed oral formulation could cause undue harm if injected intravenously, a clinical simulation was performed. The relative high, euphoric, 
and drug-liking effects of $30 \mathrm{mg}$ of intravenous morphine alone versus $30 \mathrm{mg}$ of intravenous morphine combined with $1.2 \mathrm{mg}$ of intravenous naltrexone (100:4 morphine sulfate to naltrexone hydrochloride ratio contained in MS-sNT capsules) were assessed in recreational opioid users. Results may further aid in characterizing the abuse liability of MS-sNT and the potential to reduce desirability for product tampering.

\section{Methods}

\section{Participants}

Subjects were men aged 18-50 years who had used prescription opioids to achieve a 'high' at least five times in the last 12 months, but were not physically opioid dependent. They were recreational opioid abusers who only used opioids orally or snorted. The most commonly abused opioids among the subjects were consistent with national data $^{[24]}$ and included hydrocodone/acetaminophen, oxycodone immediate release and extended release, and morphine. Subjects who used multiple drugs expressed a preference for opioids. The subjects were recruited from the database of Lifetree Clinical Research (Salt Lake City, UT, USA) and were compensated for their time during participation in the study.

Subjects were in generally good health as assessed by medical history and physical examination, laboratory tests, and ECG, and had negative urine drug screens for amphetamines, barbiturates, benzodiazepines, cocaine, and opioids upon presentation for admission to the clinic. Subjects with a history of significant neurologic, hepatic, renal, endocrine, cardiovascular, gastrointestinal, pulmonary, or metabolic disease were excluded, as were those currently in treatment for substance abuse or who had completed a substance abuse program within the previous 90 days.

Subjects could not have used, or have intended to use, any prescription or over-the-counter (OTC) medications that could interfere with the evaluation of medication during the study. Prescription medications could not have been used within 14 days of dosing and OTC medications could not have been used within 48 hours of dosing. Subjects could not ingest alcohol, grapefruit, or grapefruit juice within 48 hours of dosing or during the study.

\section{Study Design}

This single-center, randomized, double-blind, crossover study included the following three phases: (i) naloxone challenge; (ii) drug discrimination; and (iii) treatment. It was conducted in accordance with the current FDA regulations, International Conference on Harmonisation guidelines, Good Clinical Practice standards, the Declaration of Helsinki, and local ethical and legal requirements. ${ }^{[25,26]}$

\section{Naloxone Challenge Phase}

A naloxone challenge was performed on the day of admission (day 0) to rule out subjects who were physically dependent on opioids. Subjects were administered $0.1 \mathrm{mg}$ of intravenous naloxone; if there were no signs of opioid withdrawal within 30 seconds, an additional $0.3 \mathrm{mg}$ of intravenous naloxone was administered and subjects were observed for withdrawal symptoms for $20 \mathrm{~min}$ utes. Subjects were terminated from the study at the end of the naloxone challenge phase if they exhibited signs of opioid withdrawal.

\section{Drug Discrimination Phase}

Subjects were randomized to receive one intravenous injection of either $10 \mathrm{mg}$ of morphine or placebo on inpatient days 1 and 3 in a doubleblind, crossover fashion, with a 1-day washout on day 2. Ability to distinguish morphine from placebo was assessed by the investigator based on subject responses to a Drug Effects Questionnaire (DEQ; a nine-item questionnaire with a $100 \mathrm{~mm}$ visual analog scale [VAS]; $0=$ none, $100=$ extreme $^{[27]}$ and the Cole/ARCI Stimulation-Euphoria modified scale, description following in the Study Endpoints section, at designated time points following each dose. ${ }^{[23,28]}$ At the conclusion of the drug discrimination phase, the blind was broken. The investigator determined the subjects who were able to discriminate between morphine and placebo and, further, to report a more positive overall response to morphine versus placebo, using the response to the aforementioned study endpoint measures, along with clinical judgment. 


\section{Treatment Phase}

After a 1-day washout (day 4), subjects entered the treatment phase (days 5-19) consisting of three treatment periods. During each treatment period, subjects received one of the following dose sequences: (i) a single $30 \mathrm{mg}$ intravenous bolus of morphine immediately followed by a single intravenous bolus of naltrexone placebo; (ii) a single $30 \mathrm{mg}$ intravenous bolus of morphine immediately followed by a single $1.2 \mathrm{mg}$ intravenous bolus of naltrexone; or (iii) a single intravenous bolus of morphine placebo immediately followed by a single intravenous bolus of naltrexone placebo. Dosings were spaced $<30$ seconds apart. There was a 6-day outpatient washout between treatments. Subjects were required to have a negative screen for drugs and alcohol on readmission for each treatment period.

\section{Study Treatments}

Lifetree Clinical Research supplied study treatments as commercially available drug products for intravenous injection. Subjects, investigators, and those assessing the outcomes were blinded to the study drug. Subjects were assigned to treatment in order of enrollment according to a randomization schedule generated by the statistician and stored in a secured location. The pharmacist was responsible for completing a master drug accountability log documenting lot number, date, and time of drug preparation, and date and time of delivery to the study center. Treatments were provided to study centers in prefilled syringes packaged and labeled with protocol number, date, and subject initials for the drug discrimination and treatment phases. Abbott Laboratories (North Chicago, IL, USA) manufactured the morphine sulfate, King Pharmaceuticals Inc. (Bridgewater, NJ, USA) provided the naltrexone powder, and Baxter (Deerfield, IL, USA) manufactured the sodium chloride $0.9 \%$ sterile diluent.

\section{Study Endpoints}

Study assessments included pharmacodynamic, pharmacokinetic, and safety endpoints. On dos- ing days during the treatment phase, blood samples for pharmacokinetic measures were drawn at baseline (before dosing) and at scheduled time points ( 5 minutes to 24 hours postdose). Pharmacodynamic outcomes were assessed immediately following each pharmacokinetic sampling.

The primary pharmacodynamic endpoint of this study was assessed by the response to DEQ question \#5, "How high are you now?"[27] The DEQ contained nine items or subscales, each presented as a $100 \mathrm{~mm}$ VAS. The DEQ questions were as follows: (1) "Do you feel any drug effects?"; (2) "Does the drug have good effects?"; (3) "Does the drug have bad effects?"; (4) "Do you like the drug?"; (5) "How high are you now?"; (6) "Does the drug make you feel sick?"; (7) "Do you have nausea?"; (8) "Does the drug make you sleepy?"; and (9) "Does the drug make you dizzy?" Subjects were familiar with using the DEQ and the Cole/ARCI from using these scales during the drug discrimination phase. The secondary endpoint was response to the questions on the Cole/ARCI Stimulation-Euphoria subscale which consists of 15 statements that subjects rated using a 4-point scale (0-3, a modification of the 7 -point version), where $0=$ false, $1=$ more false than true, $2=$ more true than false, and $3=$ true. The total score is calculated by adding the individual scores (maximum possible total score $=45) \cdot{ }^{[23,28]}$ Since the drug-liking VAS has been used in other studies as a measure of drug attractiveness, ${ }^{[21]}$ data from DEQ question \#4, "Do you like the drug?" are reported here. Data from the remaining DEQ subscales (\#1-3 and \#6-9) and pupillometry are also summarized.

For pupillometry, lighting was controlled using a light meter to ensure that light was between 3.6 lux and 4.4 lux. Pupil diameter was measured using a pupil densitometer, ${ }^{[29]}$ with smaller values (pupillary miosis or constriction) indicating a greater morphine effect. End-tidal carbon dioxide levels, measured by noninvasive capnography, were assessed not as a safety endpoint but as an additional exploratory pharmacodynamic endpoint and are not included in this report. 


\section{Analytical Methods}

Blood samples (approximately $10 \mathrm{~mL}$ ) for pharmacokinetic analysis were collected in Vacutainer ${ }^{\circledR}$ tubes containing K2-ethylenediaminetetraacetic acid for assay of plasma morphine, naltrexone, and 6- $\beta$-naltrexol (the major naltrexone metabolite) concentrations. Immediately after collection, the tubes were gently inverted to ensure mixing of the anticoagulant with the blood; samples were pooled, split into two aliquots, and kept on ice. Within 45 minutes of collection, samples were centrifuged at $4^{\circ} \mathrm{C}$ for 10 minutes at 3000 revolutions per minute. Harvested plasma (within 30 minutes of centrifugation) was stored in an upright position at $-20 \pm 10^{\circ} \mathrm{C}$ or colder in polypropylene tubes until analysis. Two complete sets of frozen samples (a duplicate set for backup) were prepared. One complete set of samples was carefully packed in a polystyrene shipper with dry ice, tightly sealed, and shipped via overnight courier to MDS Pharma Services (now Celerion) [Lincoln, NE, USA] for analysis. The duplicate set of samples was stored at Lifetree Clinical Research until the sponsor provided direction for disposal. Concentrations originally calculated in conventional units were converted to SI units to allow direct comparison of number of molecules of morphine versus naltrexone and 6 - $\beta$-naltrexol. The molecular weights used for the calculations were morphine monomer 285.34, naltrexone 341.4, and 6- $\beta$-naltrexol 343.42 (e.g. to convert $50 \mathrm{ng} / \mathrm{mL}$ morphine to $\mathrm{nmol} / \mathrm{L}$, divide $50 \mathrm{ng} / \mathrm{mL} / \mathrm{molecular}$ weight and multiply by 1000 , which yields $175 \mathrm{nmol} / \mathrm{L}$ ). Plasma concentrations of the analytes were measured using validated liquid chromatography-tandem mass spectrometry with the following analytical ranges: 0.876$175 \mathrm{nmol} / \mathrm{L}$ for morphine, $0.0117-1.465 \mathrm{nmol} / \mathrm{L}$ for naltrexone, and $0.0116-4.66 \mathrm{nmol} / \mathrm{L}$ for 6 - $\beta$-naltrexol. Samples with $<0.0116 \mathrm{nmol} / \mathrm{L}$ 6 - $\beta$-naltrexol were re-assayed with a more sensitive method (range $0.00146-0.0728 \mathrm{nmol} / \mathrm{L}$ ).

\section{Safety Outcomes}

Safety was evaluated by vital signs, pulse oximetry, physical examinations, ECGs, clinical laboratory tests, and adverse events (AEs). All safety analyses were based on the double-blind safety population that included all randomized subjects who received one or more doses of study medication (intravenous morphine, intravenous naltrexone, or intravenous placebo) in the treatment phase.

\section{Statistical Analysis}

Sample size was determined using experience with studies of similar design that evaluated differences between the two active treatments. It was expected that approximately 76 subjects would be screened, with 40 participating in the naloxone challenge, 34 continuing into the drug discrimination phase, and 24 entering the treatment phase.

For each subject in the pharmacodynamic population (received one or more study treatments in the double-blind treatment phase and provided one or more subsequent pharmacodynamic assessments during that phase), the maximum-effect score within a period $\left(\mathrm{E}_{\max }\right)$ and time to maximum effect $\left(\mathrm{TE}_{\max }\right)$ were identified for each treatment period. Each pharmacodynamic assessment was summarized by treatment using descriptive statistics at each time point. In addition, the mean for each pharmacodynamic assessment over time was plotted for each treatment.

WinNonlin ${ }^{\circledR}$ version 5.1 (Pharsight Corp., Mountain View, CA, USA) was used to calculate individual subject pharmacodynamic outcomes. All other analyses and tabulations were performed using SAS ${ }^{\circledR}$ version 9.1.3 (SAS Institute Inc., Cary, NC, USA) on a PC platform. Each pharmacodynamic assessment was analyzed and $\mathrm{p}$-values determined using a linear mixed model (PROC MIXED, SAS) with fixed effects for sequence, period, and treatment arm, and a random effect for subject nested in sequence. Adjustments for multiple comparisons were made using the Benjamini and Hochberg ${ }^{[30]}$ method in SAS PROC MULTITEST. Least squares (LS) means along with $95 \%$ confidence intervals were provided for each treatment arm and for all pairwise comparisons between treatment arms. The $\mathrm{E}_{\max }$ was used for pharmacodynamic analyses. The $\mathrm{E}_{\max }$ values were expected to be log-normally 
distributed and were transformed prior to analysis by taking the natural logarithm. Zero values were replaced with 0.0001 as an arbitrary small value because a log transformation is not possible with zero values. Descriptive statistics as well as estimates of geometric LS means and 95\% confidence intervals were calculated.

The pharmacokinetic analyses were based on all available post-dosing pharmacokinetic data $(n=28)$. For each subject, the pharmacokinetic assessments were determined using a noncompartmental approach for all parameters in PhAST version 2.3-001 software (1999; Phoenix Automated Statistics and Tabulation; manufactured by Phoenix International Life Sciences, located in Montreal, QC, Canada), except concentration at time $0\left[\mathrm{C}_{0}\right] ; \mathrm{C}_{0}$ was estimated with ADAPT II Release 4 (1997, Biomedical Simulations Resource, University of Southern California, Los Angeles, CA, USA). Summary statistics for plasma concentrations of morphine, naltrexone, and 6 - $\beta$-naltrexol were calculated by time and treatment. For data plotting, plasma concentration values that were below the limit of quantification (BLQ) embedded between two measurable concentrations were set to missing; however, BLQ values occurring after the last measurable plasma concentration were set to zero. For the purpose of the compartmental pharmacokinetic analysis $\left(\mathrm{C}_{0}\right.$ calculations), all BLQ values occurring after the first measurable plasma concentration were set to missing.

\section{Results}

\section{Participants}

The study was conducted between 20 September 2007 and 21 November 2007. Of the 41 subjects who were screened, 29 were enrolled. One subject who failed the drug discrimination phase was discontinued. All 28 subjects receiving one or more doses of study drug during the double-blind treatment phase were included in the pharmacodynamic and safety populations. The evaluable pharmacodynamic population (completed the morphine plus naltrexone treatment and one or more other treatments in the double-blind treat- ment phase) included 27 subjects. One subject who had completed the morphine and the placebo arms was discontinued for noncompliance and his data were excluded from the evaluable pharmacodynamic population. A second subject, who was included in the evaluable pharmacodynamic population, was discontinued before completing placebo treatment due to an AE (a tooth infection unrelated to study drug).

In the safety population, the age range was 18-36 years (mean \pm standard deviation: 23.8 \pm 4.5 years). Twenty-five subjects $(89.3 \%)$ were White, two were African American, and one was Asian.
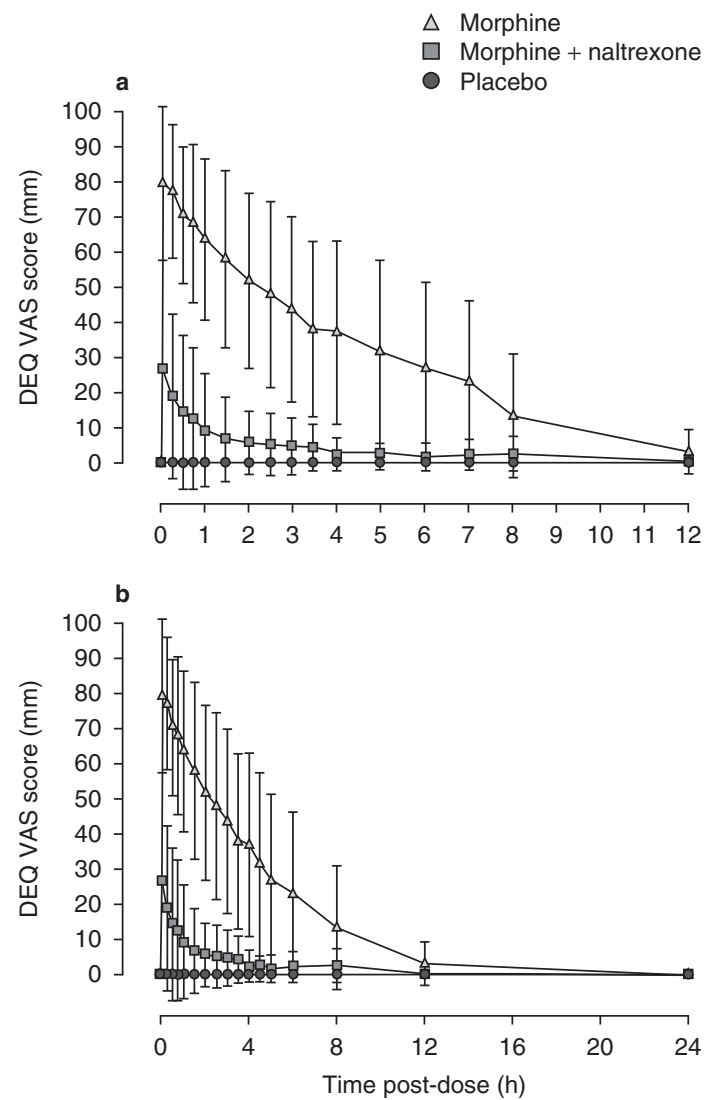

Fig. 1. Data (mean \pm standard deviation) are shown for the Drug Effects Questionnaire (DEQ) question \#5, "How high are you now?" after intravenous administration of morphine $(n=28)$, morphine plus naltrexone $(n=27)$, and placebo $(n=27)$ as a function of time (ordinate) since drug administration in the pharmacodynamic population. Data for (a) 12 hours and (b) 24 hours post-dose. VAS = visual analog scale. 
Table I. Pharmacodynamic outcomes

\begin{tabular}{|c|c|c|c|}
\hline Parameter & Placebo $(n=26)$ & Morphine + naltrexone $(n=27)$ & Morphine $(n=27)$ \\
\hline \multicolumn{4}{|c|}{ DEQ \#5: “How high are you now?” (primary outcome measure) } \\
\hline \multicolumn{4}{|l|}{$\mathrm{E}_{\max }(\mathrm{mm})$} \\
\hline $\operatorname{mean}^{\mathrm{a}} \pm \mathrm{SD}$ & $0.0 \pm 0.0$ & $29.8 \pm 26.4^{\mathrm{b}, \mathrm{c}}$ & $85.2 \pm 12.9^{\mathrm{C}}$ \\
\hline range & $0-0$ & $0-93.0$ & $55.0-100.0$ \\
\hline \multicolumn{4}{|l|}{$\mathrm{TE}_{\max }(\mathrm{h})$} \\
\hline median & 0.0 & 0.1 & 0.1 \\
\hline range & $0-0$ & $0-6.0$ & $0.1-0.8$ \\
\hline \multicolumn{4}{|l|}{$\mathrm{AUE}_{2}(\mathrm{~h} \bullet \mathrm{mm})$} \\
\hline $\operatorname{mean}^{\mathrm{a}} \pm \mathrm{SD}$ & $0.0 \pm 0.0$ & $22.4 \pm 28.2$ & $129.3 \pm 37.2$ \\
\hline range & $0-0$ & $0-115.5$ & $32.3-191.3$ \\
\hline \multicolumn{4}{|l|}{$\mathrm{AUE}_{8}(\mathrm{~h} \bullet \mathrm{mm})$} \\
\hline $\operatorname{mean}^{\mathrm{a}} \pm \mathrm{SD}$ & $0.0 \pm 0.0$ & $41.2 \pm 40.4$ & $315.0 \pm 160.5$ \\
\hline range & $0-0$ & $0-142.5$ & $45.8-621.1$ \\
\hline \multicolumn{4}{|c|}{ Cole/ARCI Stimulation-Euphoria (secondary outcome measure) } \\
\hline \multicolumn{4}{|l|}{$\mathrm{E}_{\max }(\mathrm{mm})$} \\
\hline mean $^{\mathrm{a}} \pm \mathrm{SD}$ & $1.3 \pm 3.1$ & $13.7 \pm 9.5^{\mathrm{b}, \mathrm{c}}$ & $27.8 \pm 11.2^{\mathrm{c}}$ \\
\hline range & $0-15.0$ & $0-39.0$ & $4.0-45.0$ \\
\hline \multicolumn{4}{|l|}{$\mathrm{TE}_{\max }(\mathrm{h})$} \\
\hline median & 0.0 & 0.1 & 0.3 \\
\hline range & $0-24.0$ & $0-24.0$ & $0.1-2.5$ \\
\hline \multicolumn{4}{|c|}{$\mathrm{AUE}_{2}(\mathrm{~mm} \bullet$ unit $)$} \\
\hline $\operatorname{mean}^{\mathrm{a}} \pm \mathrm{SD}$ & $-0.2 \pm 1.0$ & $12.9 \pm 15.0$ & $43.5 \pm 23.1$ \\
\hline range & -4.7 to 0.6 & -5.0 to 61.9 & $0.5-85.5$ \\
\hline \multicolumn{4}{|c|}{$\mathrm{AUE}_{8}(\mathrm{~mm} \bullet$ unit $)$} \\
\hline $\operatorname{mean}^{\mathrm{a}} \pm \mathrm{SD}$ & $-0.9 \pm 3.1$ & $31.3 \pm 33.5$ & $118.3 \pm 73.6$ \\
\hline range & -14.7 to 0.1 & -21.5 to 113.4 & $0.5-250.1$ \\
\hline \multicolumn{4}{|c|}{ DEQ \#4: drug liking (additional outcome measure) } \\
\hline \multicolumn{4}{|l|}{$\mathrm{E}_{\max }(\mathrm{mm})$} \\
\hline mean $^{a} \pm S D$ & $0.0 \pm 0.0$ & $38.9 \pm 30.5^{\mathrm{b}, \mathrm{c}}$ & $81.4 \pm 17.1^{\mathrm{C}}$ \\
\hline range & $0-0$ & $0-100$ & $37.0-100$ \\
\hline \multicolumn{4}{|l|}{$\mathrm{TE}_{\max }(\mathrm{h})$} \\
\hline median & 0.0 & 0.1 & 0.3 \\
\hline range & $0-0$ & $0-8.0$ & $0.1-1.0$ \\
\hline \multicolumn{4}{|c|}{$\mathrm{AUE}_{2}(\mathrm{~mm} \bullet$ unit $)$} \\
\hline $\operatorname{mean}^{\mathrm{a}} \pm \mathrm{SD}$ & $0.0 \pm 0.0$ & $32.7 \pm 34.8$ & $130.6 \pm 41.1$ \\
\hline range & $0-0$ & $0-138.6$ & $33.7-195.8$ \\
\hline \multicolumn{4}{|c|}{$\mathrm{AUE}_{8}(\mathrm{~mm} \bullet$ unit $)$} \\
\hline $\operatorname{mean}^{\mathrm{a}} \pm \mathrm{SD}$ & $0.0 \pm 0.0$ & $68.1 \pm 78.0$ & $374.4 \pm 196.4$ \\
\hline range & $0-0$ & $0-345.3$ & $41.2-795.6$ \\
\hline
\end{tabular}

a Arithmetic mean.

b $\mathrm{p}<0.0001$ vs morphine.

c $p<0.0001$ vs placebo.

$\mathbf{A R C l}=$ Addiction Research Center Inventory; $\mathbf{A U E}_{\boldsymbol{x}}=$ area under the effect curve from time 0 to $x$ hours; $\mathbf{D E Q}=$ Drug Effects Questionnaire; $E_{\max }=$ maximum effect; $T_{E_{\max }}=$ time to maximum effect. 

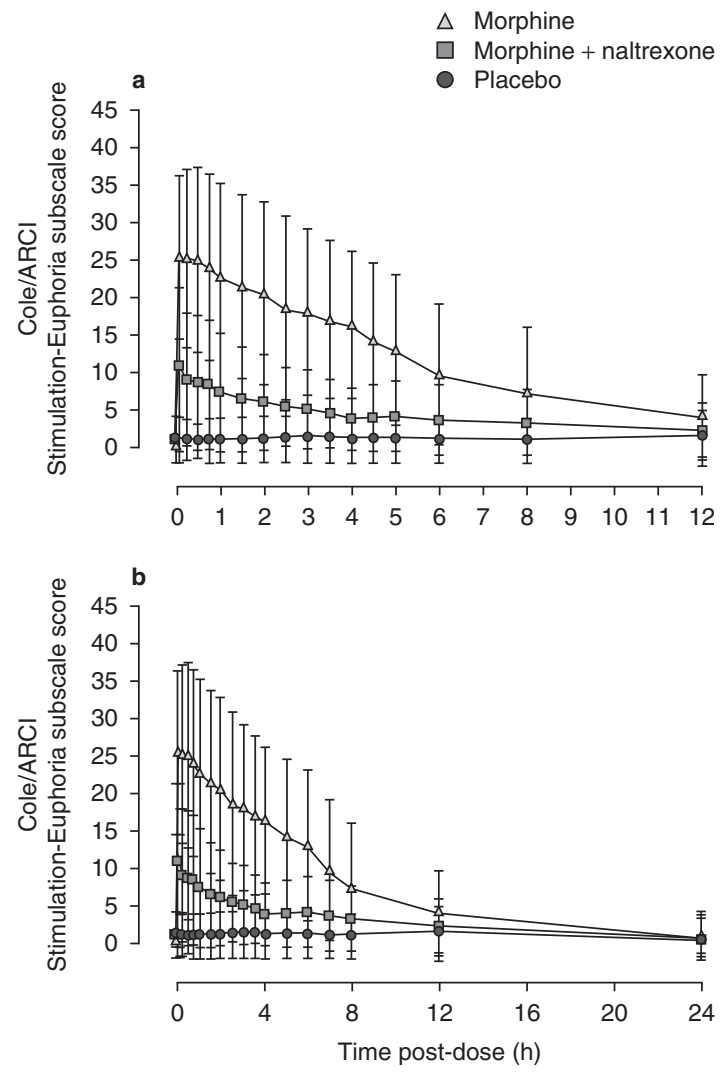

Fig. 2. Data (mean \pm standard deviation) are shown for the Cole/ Addiction Research Center Inventory (ARCl) Stimulation-Euphoria subscale scores after intravenous administration of morphine $(n=28)$, morphine plus naltrexone $(n=27)$, and placebo $(n=27)$ as a function of time (ordinate) since drug administration in the pharmacodynamic population. Data for (a) 12 hours and (b) 24 hours post-dose.

\section{Pharmacodynamic Outcomes}

Mean DEQ \#5 (“How high are you now?') values over time are illustrated in figure 1 . The median $\mathrm{TE}_{\max }$ was 6 minutes $(0.1$ hour) for the morphine and morphine plus naltrexone treatments, and 0 minutes for placebo (see table I). The arithmetic mean ( \pm standard deviation) score for the $E_{\max }$ was significantly greater for morphine than morphine plus naltrexone or placebo $(85.2 \pm 12.9 \mathrm{~mm}$ vs $29.8 \pm 26.4 \mathrm{~mm}$ vs $0.0 \pm 0.0 \mathrm{~mm}$, respectively; $\mathrm{p}<0.0001)$. This difference was statistically significant across all three treatment groups as well as between treatment groups in pairwise comparisons. Mean area under the effect curve (AUE) was greater when morphine was administered alone than when coadministered with naltrexone (see table I). The median difference in DEQ \#5 $\mathrm{E}_{\max }$ score between morphine and morphine plus naltrexone was $62.0 \mathrm{~mm}$ (range, $7.0-93.0 \mathrm{~mm}$ ). At maximum effect, only 2 of 27 $(7.4 \%)$ subjects experienced less than a 10 -point difference.

The results for the Cole/ARCI StimulationEuphoria subscale assessments (see table I and figure 2) reinforce the findings of the primary pharmacodynamic assessment of 'high'. Median $\mathrm{TE}_{\max }$ for morphine plus naltrexone was 0.1 hour and for morphine was 0.3 hours. Arithmetic mean $\mathrm{E}_{\max }$ scores were significantly greater for morphine than for morphine plus naltrexone or placebo
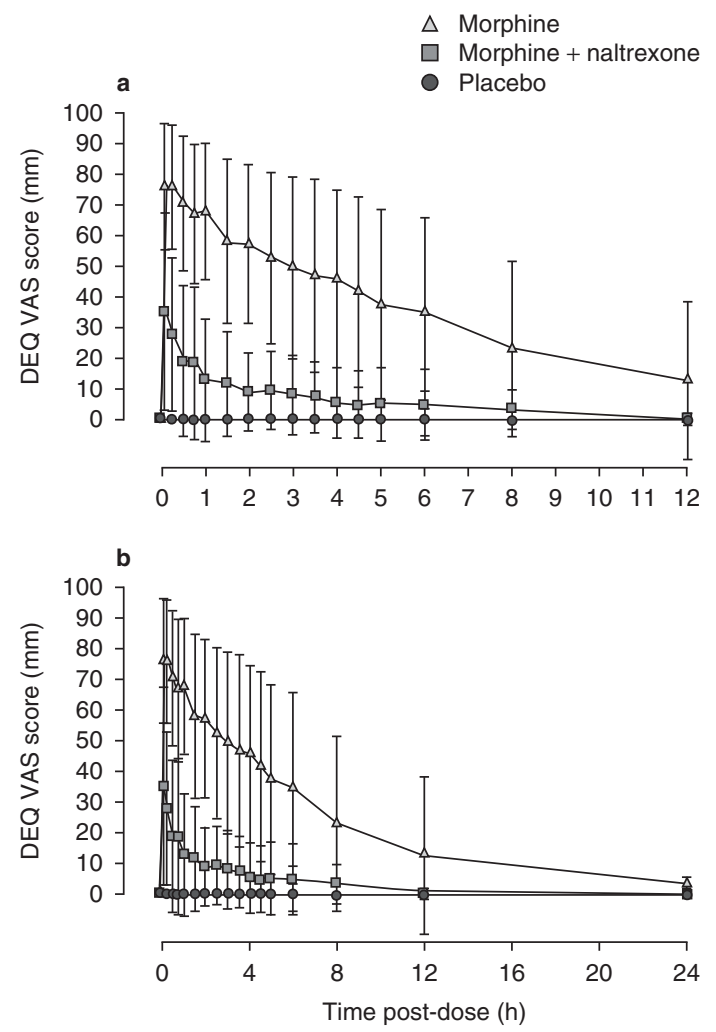

Fig. 3. Data (mean \pm standard deviation) are shown for the Drug Effects Questionnaire (DEQ) question \#4, "Do you like the drug?" after intravenous administration of morphine $(n=28)$, morphine plus naltrexone $(n=27)$, and placebo $(n=27)$ as a function of time (ordinate) since drug administration in the pharmacodynamic population. Data for (a) 12 hours and (b) 24 hours post-dose. VAS = visual analog scale. 
Table II. Exploratory outcome: pupillometry

\begin{tabular}{|c|c|c|c|}
\hline Parameter & Placebo $(n=26)$ & Morphine + naltrexone $(n=27)$ & Morphine $(n=27)$ \\
\hline \multicolumn{4}{|l|}{$\overline{E_{\min }(m m)}$} \\
\hline $\operatorname{mean}^{\mathrm{a}} \pm \mathrm{SD}$ & $4.4 \pm 0.8$ & $3.4 \pm 0.6^{b, c}$ & $2.4 \pm 0.3^{\mathrm{C}}$ \\
\hline range & $3-6$ & $2-4$ & $2-3$ \\
\hline \multicolumn{4}{|l|}{$\mathrm{TE}_{\min }(\mathrm{h})$} \\
\hline median & 3.0 & 4.0 & 0.8 \\
\hline range & $0-24$ & $0-12$ & $0.1-2.5$ \\
\hline \multicolumn{4}{|l|}{$\mathrm{AUE}_{2}(\mathrm{~h} \bullet \mathrm{mm})$} \\
\hline $\operatorname{mean}^{\mathrm{a}} \pm \mathrm{SD}$ & $0.0 \pm 0.9$ & $-1.3 \pm 1.5$ & $-5.0 \pm 1.8$ \\
\hline range & -2.0 to 1.4 & -3.4 to 2.3 & -8.1 to -1.4 \\
\hline \multicolumn{4}{|l|}{$\mathrm{AUE}_{8}(\mathrm{~h} \bullet \mathrm{mm})$} \\
\hline $\operatorname{mean}^{\mathrm{a}} \pm \mathrm{SD}$ & $0.3 \pm 4.8$ & $-8.5 \pm 6.8$ & $-18.8 \pm 8.0$ \\
\hline range & -10.6 to 9.1 & -19.1 to 6.4 & -32.7 to -4.7 \\
\hline \multicolumn{4}{|c|}{ a Arithmetic mean. } \\
\hline \multirow{2}{*}{\multicolumn{4}{|c|}{$\begin{array}{l}\text { b } p<0.0001 \text { vs morphine. } \\
\text { c } p<0.0001 \text { vs placebo. }\end{array}$}} \\
\hline $\mathrm{p}<0.0001 v$ & & & \\
\hline \multicolumn{4}{|c|}{$\begin{array}{l}\mathbf{A U E}_{\boldsymbol{x}}=\text { area under the effect curve from time } 0 \text { to } x \text { hours; } \mathbf{E}_{\min }=\text { minimum pupil diameter (maximum effect); } \mathbf{S D}=\text { standard deviation; } \\
\mathbf{T E}_{\min }=\text { time to minimum pupil diameter (maximum effect). }\end{array}$} \\
\hline
\end{tabular}

( $27.8 \mathrm{~mm}$ vs $13.7 \mathrm{~mm}$ vs $1.3 \mathrm{~mm}$, respectively; $\mathrm{p}<0.0001)$. Mean AUE was greater when morphine was administered alone than when administered with naltrexone (see table I). Overall, $71 \%$ of subjects reported a reduction in euphoria with morphine plus naltrexone compared with morphine alone. ${ }^{[20]}$

Arithmetic mean values over time for DEQ question \#4, "Do you like the drug?" are shown in figure 3. Median $\mathrm{TE}_{\max }$ for morphine plus naltrexone was 0.1 hour and for morphine was 0.3 hours. Arithmetic mean score for $\mathrm{E}_{\max }$ for drug liking was significantly greater for morphine than morphine plus naltrexone or placebo $(81.4 \mathrm{~mm}$ vs $38.9 \mathrm{~mm}$ vs $0.0 \mathrm{~mm}$, respectively; $\mathrm{p}<0.0001)$ and mean AUE was greater when morphine was administered alone than when administered with naltrexone (see table I).

For each of the remaining seven DEQ questions, the $\mathrm{E}_{\max }$ for morphine was greater than for morphine plus naltrexone and placebo. Statistically significant geometric mean differences in $\mathrm{E}_{\max }$ were detected across all three treatments $(p<0.0001)$. For the 'desirable' (positive subjective effects) DEQ outcomes of \#1 (drug effects), \#2 (feeling good effects), and \#4 (liking the drug), the median $\mathrm{TE}_{\max }$ was similar or slightly shorter for morphine than morphine plus naltrexone. Median $\mathrm{TE}_{\max }$ values for the 'undesirable' (negative subjective effects) DEQ outcomes of \#3 (bad effects), \#6 (feeling sick), \#7 (having nausea), \#8 (feeling sleepy), and \#9 (feeling dizzy) were earlier for morphine plus naltrexone than for morphine. ${ }^{[21]}$

\section{Pupillometry Analysis}

The peak morphine drug effect was observed when the pupil diameter was smallest (indicative of morphine-induced constriction). Minimum pupil diameter is noted as $\mathrm{E}_{\min }$, the baseline for comparison when noting increase in pupil size. Following intravenous administration of morphine alone, the mean $\mathrm{E}_{\min }(2.4 \mathrm{~mm})$ was significantly reduced relative to placebo $(4.4 \mathrm{~mm})$ and morphine plus naltrexone $(3.4 \mathrm{~mm})[\mathrm{p}<0.0001$ for both comparisons]. Median time to reach this minimum pupil diameter $\left(\mathrm{TE}_{\min }\right)$ after morphine alone was rapid ( 0.8 hours) compared with placebo (3.0 hours) and morphine plus naltrexone (4.0 hours). The miotic effect was temporally delayed relative to morphine alone when morphine was administered intravenously with naltrexone. 
Mean AUE from time 0 to 8 hours for miosis was smaller $(-18.8 \mathrm{~h} \bullet \mathrm{mm}$ vs $-8.5 \mathrm{~h} \bullet \mathrm{mm})$ for morphine alone relative to morphine plus naltrexone and placebo (see table II and figure 4).

\section{Pharmacokinetics}

Plasma morphine concentration-time profiles and pharmacokinetic parameters were similar for intravenous morphine alone compared with concomitant intravenous naltrexone administration, including extent of exposure (area under the
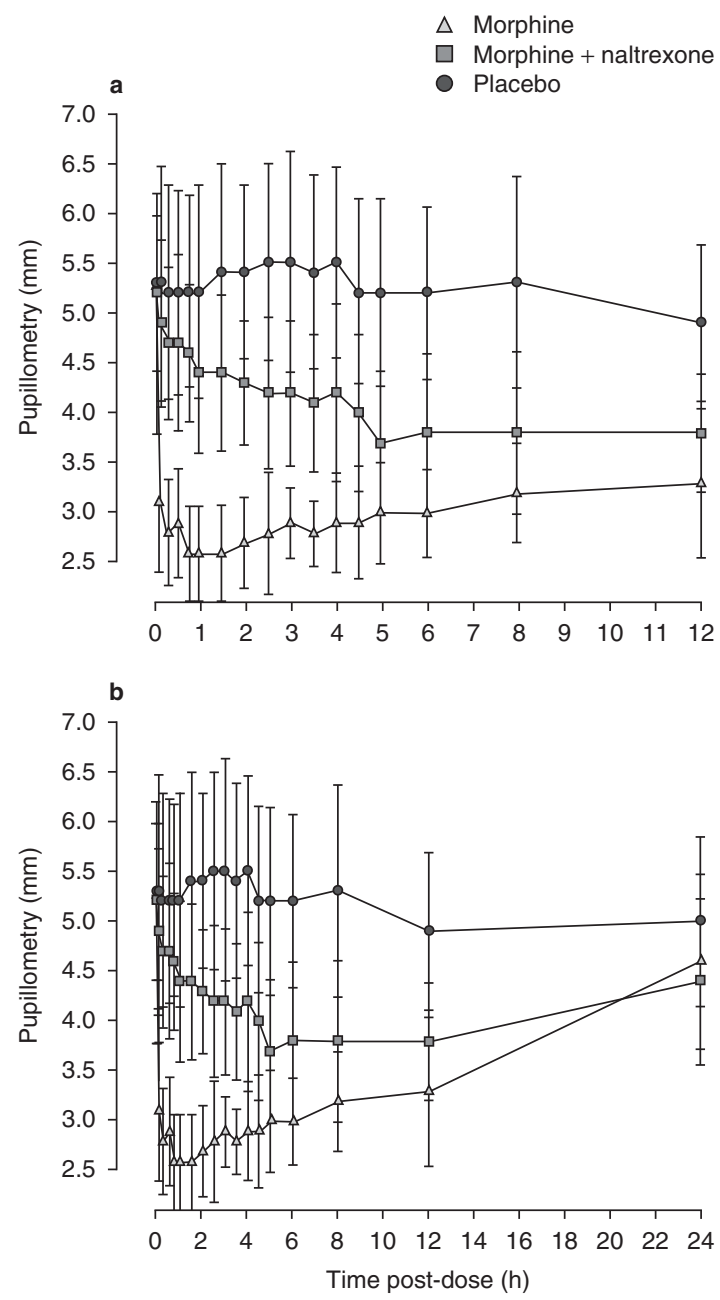

Fig. 4. Pupillometry data (mean \pm standard deviation) over time (pharmacodynamic population). Data for (a) 12 hours and (b) 24 hours post-dose. plasma drug concentration-time curve) at the measured time points (see table III and figure 5). This similarity demonstrated that the coadministration of naltrexone and morphine had no apparent effect on the morphine pharmacokinetics when compared with morphine administered alone. Following single intravenous bolus administrations, morphine, naltrexone, and 6- $\beta$-naltrexol reached peak concentrations immediately after dosing and then decreased in a multi-exponential manner (see figure 5). Pharmacokinetic assessments of morphine, naltrexone, and 6- $\beta$-naltrexol are shown in table III.

\section{Pharmacokinetic-Pharmacodynamic Relationship}

Based on additional exploratory analysis, figure $6 \mathrm{a}$ shows a hysteresis plot of percentage change in euphoria abatement versus mean plasma naltrexone concentration using the Cole/ARCI Stimulation-Euphoria subscale over time. Subjects who did not experience euphoria (18.5\%, 5 of 27) were not included in the analysis. The plasma naltrexone rapidly reached its peak level $(21.4 \mathrm{nmol} / \mathrm{L})$ by 5 minutes and then decreased. This is related to a median $63 \%$ abatement of the morphine-induced euphoria. The naltrexone-induced euphoria abatement continued and reached a maximum of $80 \%$ by 30 minutes. Figure $6 \mathrm{~b}$ shows the increase in pupil size (relative to that with morphine) plotted against plasma naltrexone concentration over time. The mean naltrexone peak plasma level at 5 minutes is related to a $2 \mathrm{~mm}$ increase in pupil size showing the blocking of the morphine-induced pupil constriction. This effect was maintained until 45 minutes and gradually decreased in relation to the lower plasma naltrexone levels over time.

\section{Safety}

In this study, 21 of 28 (75\%) subjects experienced a total of 69 AEs. Nineteen (67.9\%) subjects experienced 50 of these AEs when treated with morphine alone. By contrast, 9 of 27 (33.3\%) subjects experienced 17 AEs during treatment with morphine plus naltrexone and two (7.4\%) subjects taking placebo reported two events (see table IV). The most frequently reported AEs were 
Table III. Summary of pharmacokinetic assessments

\begin{tabular}{|c|c|c|c|c|}
\hline \multirow[t]{2}{*}{ Parameter } & \multirow{2}{*}{$\begin{array}{l}\text { Morphine alone }(n=28) \\
\text { plasma morphine }\end{array}$} & \multicolumn{3}{|c|}{ Morphine + naltrexone $(n=26)$} \\
\hline & & plasma morphine & plasma naltrexone & plasma 6- $\beta$-naltrexol \\
\hline$\overline{\mathrm{C}_{0}(\mathrm{nmol} / \mathrm{L})^{\mathrm{a}}}$ & $2895(94.4 \%)$ & $3235(92.5 \%)$ & $32(77.2 \%)$ & NA \\
\hline $\mathrm{AUC}_{2}(\mathrm{nmol} \bullet \mathrm{h} / \mathrm{L})^{\mathrm{a}}$ & $624(28.2 \%)$ & $641(29.6 \%)$ & $15(19.4 \%)$ & $6(25.8 \%)$ \\
\hline $\mathrm{AUC}_{8}(\mathrm{nmol} \bullet \mathrm{h} / \mathrm{L})^{\mathrm{a}}$ & $911(23.2 \%)$ & $967(25.3 \%)$ & $24(20.5 \%)$ & $22(18.4 \%)$ \\
\hline $\mathrm{AUC}_{\mathrm{t}}(\mathrm{nmol} \bullet \mathrm{h} / \mathrm{L})^{\mathrm{a}}$ & $1016(21.1 \%)$ & $1104(23.7 \%)$ & $25(21.0 \%)$ & $42(18.4 \%)$ \\
\hline $\mathrm{AUC}_{\infty}(\mathrm{nmol} \bullet \mathrm{h} / \mathrm{L})^{\mathrm{a}}$ & $1100(15.4 \%)$ & $1167(25.4 \%)$ & $25(21.3 \%)$ & $58(18.2 \%)$ \\
\hline$t_{1 / 2}(h)^{b}$ & $9.62(5.44)$ & $8.32(3.68)$ & $3.12(1.0)$ & $13.2(2.56)$ \\
\hline $\mathrm{V}_{\mathrm{ss}}(\mathrm{L})^{\mathrm{b}}$ & $394(215)$ & $336(136.4)$ & $299(59.8)$ & NA \\
\hline $\mathrm{CL}_{\mathrm{t}}(\mathrm{L} / \mathrm{h})^{\mathrm{b}}$ & $72.8(10.7)$ & $69.7(14.43)$ & $128(26.5)$ & NA \\
\hline
\end{tabular}

a Geometric mean (CV\%).

b Arithmetic mean (SD).

$\mathbf{A U C} \mathbf{C}_{\mathbf{t}}=$ area under the plasma concentration curve at time $t$, where $t$ is either 12 hours or 24 hours depending on the time of last measureable concentration; $\mathbf{A} \mathbf{U} \mathbf{C}_{\infty}=$ area under the plasma drug concentration-time curve from time zero to infinity; $\mathbf{A U C}_{\boldsymbol{x}}=$ area under the plasma drug concentration-time curve from 0 to $x$ hours; $\mathbf{C}_{0}=$ anticipated initial plasma drug concentration; $\mathbf{C L}_{\mathbf{t}}=$ total plasma clearance; $\mathbf{C V}=\mathbf{c o e f f i c i e n t}$ of variation; $\mathbf{N A}=$ not available; $\mathbf{t}_{1 / 2}=$ terminal half-life; $\mathbf{V}_{\mathbf{s s}}=$ volume of distribution at steady state.

pruritus, nausea, and vomiting (see table IV). One subject discontinued because of an AE (tooth infection). There were no deaths or serious AEs. No clinically significant abnormal laboratory values were reported. One subject reported a moderately severe episode of vasovagal syncope, which was considered by the investigator to be unrelated to study drug and resolved spontaneously on the day of onset. No study drugrelated changes in vital signs or physical findings were noted.

\section{Discussion}

The goal of this study was to assess the intravenous abuse liability of MS-sNT by simulating the intravenous abuse of the product by recreational opioid abusers. The relative effects of intravenous morphine alone or in combination with intravenous naltrexone in a $100: 4$ ratio on high, euphoria, and drug liking were assessed.

For the primary endpoint DEQ \#5 ("How high are you now?") maximum effect achieved with morphine alone was approximately 3 -fold greater than for morphine plus naltrexone. The maximum effect for placebo was $0.0 \mathrm{~mm}$. On the Cole/ARCI Stimulation-Euphoria subscale, the euphoric effect of morphine alone was approximately twice that of morphine plus naltrexone.
Maximum effect for both treatments was significantly different from placebo. The maximum effect for drug liking of morphine alone was approximately 2 -fold greater than for morphine plus naltrexone. Results consistently demonstrated greater subjective effects when morphine was taken intravenously alone than when it was administered with the naltrexone.

The remaining pharmacodynamic analyses (DEQ \#1-3 and \#6-9) demonstrated that, in most instances, the mean maximum values for morphine alone were significantly greater than the corresponding values for morphine plus naltrexone and placebo groups. For each DEQ measure, morphine plus naltrexone provided significantly greater effect compared with placebo, but with a sufficient dosage of naltrexone to significantly mitigate the morphine subjective effects. Compared with morphine alone, the subjectively appealing attributes of the drug (such as feeling drug effects, feeling good effects, and liking the drug) occurred more slowly, while the unappealing attributes became evident more quickly after the morphine plus naltrexone combination. This suggests that the presence of naltrexone contributed appreciably to the abatement of morphine high and euphoria without decreasing the unpleasant effects (e.g. nausea, sleepiness) associated with morphine use. 
An analysis performed subsequent to this study suggested that differences of $8-10 \mathrm{~mm}$ in VAS ratings of 'high' indicate clinical significance. ${ }^{[31]}$ As shown in figure 1 in the current study, the mean difference in VAS scores for DEQ question \#5, "How high are you now?" observed between morphine plus naltrexone and morphine alone remained greater than $10 \mathrm{~mm}$ from 5 minutes
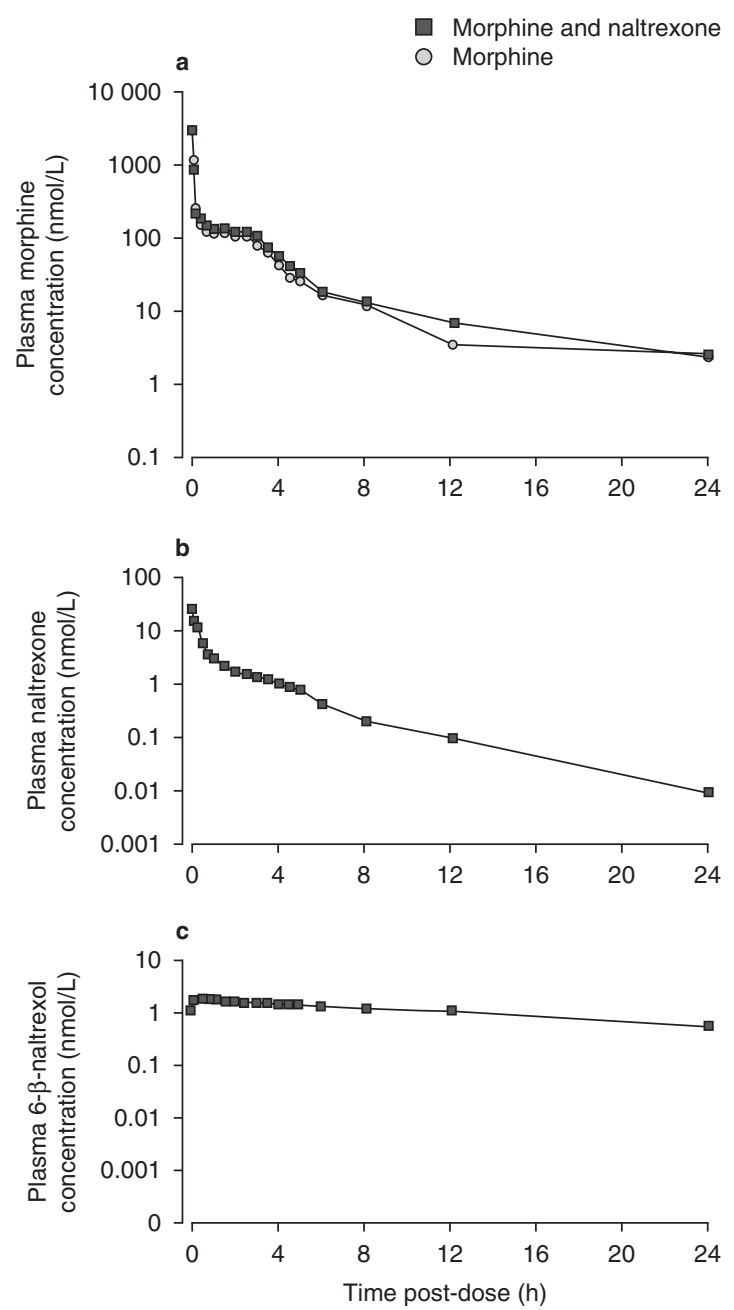

Fig. 5. Mean (mean \pm standard error of the mean) plasma concentration-time plots for plasma (a) morphine, (b) naltrexone, and (c) 6-ßnaltrexol after intravenous administration of morphine $(n=28)$ or morphine plus naltrexone $(n=26)$ as a function of time (ordinate) since drug administration in the evaluable pharmacodynamic population. post-dose through 8 hours post-dose. At maximum effect, only 2 of 27 (7.4\%) subjects experienced less than a 10-point difference.

In the context of this clinical simulation, the study treatments were well tolerated. It is likely that adverse consequences would be much greater in cases of parenteral abuse of MS-sNT due to the presence of excipients such as talc. However, results of this study should serve as an indication that, in addition to the potential harm caused by tampering with and injecting MS-sNT, the desired high would not be attained.

As morphine causes miosis, ${ }^{[29,32,33]}$ pupillometry measurements were introduced as an objective measure of opioid effect. The geometric mean $\mathrm{E}_{\text {min }}$ was significantly smaller after intravenous morphine than after placebo or after morphine plus naltrexone. Furthermore, the median $\mathrm{TE}_{\min }$ was significantly quicker with morphine alone than for placebo or morphine plus naltrexone. In addition, a relationship was observed between plasma naltrexone levels and pupil dilation over time in the hysteresis plot, showing an increase in pupil size (relative to morphine alone) of $2 \mathrm{~mm}$ for maximum naltrexone plasma levels after 5 minutes. This finding suggests that the morphine-induced decrease in pupil diameter was inhibited by naltrexone. This effect was sustained for 45 minutes and then gradually decreased as the plasma naltrexone levels decreased. The persistence of a smaller pharmacodynamic effect (continued difference between morphine and morphine plus naltrexone) over the remainder of the 12-hour period is likely caused by a dose effect related to receptor binding. The relatively smaller dose of naltrexone combined with high hepatic clearance may result in reduced temporal effect from that of the much higher dose of morphine. The timing of morphine-induced effects observed in this study is in agreement with that from a recently published study in which intravenous morphine was administered to intravenousexperienced recreational opioid users. ${ }^{[34]}$

A pharmacokinetic-pharmacodynamic relationship was also observed for the plasma naltrexone levels in relation to the morphine-induced euphoria as measured by the Cole/ARCI StimulationEuphoria subscale. The plasma naltrexone versus 

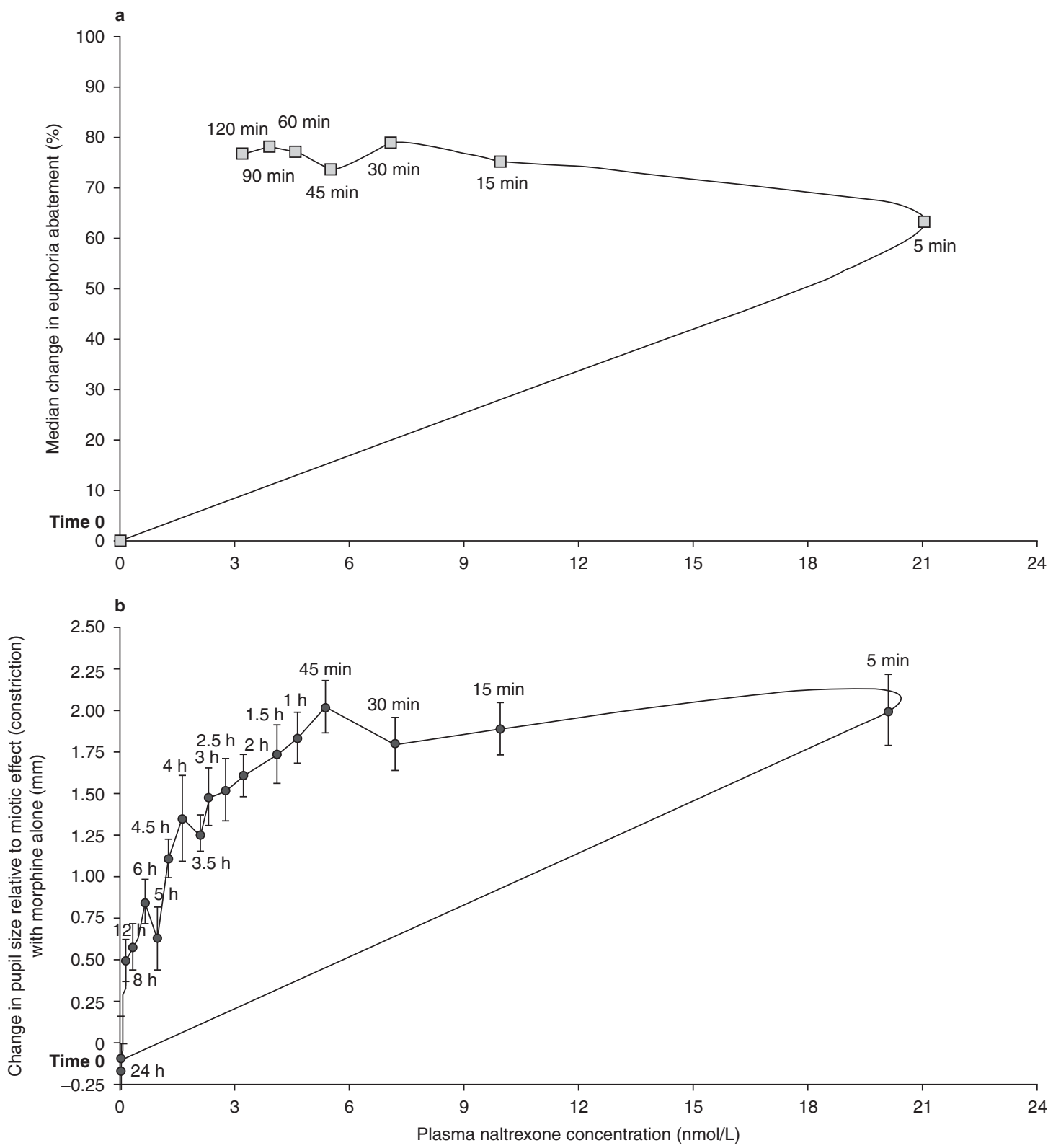

Fig. 6. Data are shown for the hysteresis plot of (a) percentage change in euphoria abatement vs naltrexone concentration over time after administration of intravenous (IV) morphine followed by IV naltrexone $(n=22)$; and $(b)$ increase in pupil size vs naltrexone concentration over time after administration of IV morphine followed by IV naltrexone $(n=27)$.

euphoria abatement and versus change in pupil diameter hysteresis curves validates the naltrexone effect on the subjective responses.
Although administered within 30 seconds, it is possible that the sequential administration of morphine and naltrexone allowed a temporary 
Table IV. Most frequently reported (one or more) adverse events (AEs) [n (\%)]

\begin{tabular}{llll}
\hline AE & Placebo $(\mathrm{n}=27)$ & Morphine + naltrexone $(\mathrm{n}=27)$ & Morphine $(\mathrm{n}=28)$ \\
\hline Subjects reporting $\geq 1 \mathrm{AE}$ & $2(7.4)$ & $9(33.3)$ & $19(67.9)$ \\
Pruritus & $0(0.0)$ & $1(3.7)$ & $10(35.7)$ \\
Nausea & $1(3.7)$ & $3(11.1)$ & $9(32.1)$ \\
Vomiting & $0(0.0)$ & $1(3.7)$ & $7(25.0)$ \\
Headache & $0(0.0)$ & $4(14.8)$ & $2(7.1)$ \\
Dizziness & $0(0.0)$ & $2(7.4)$ & $3(10.7)$ \\
Nasal discomfort & $0(0.0)$ & $0(0.0)$ & $3(10.7)$ \\
Hiccups & $0(0.0)$ & $0(0.0)$ & $2(7.1)$ \\
Irritability & $0(0.0)$ & $0(0.0)$ & $2(7.1)$ \\
Dysuria & $0(0.0)$ & $0(0.0)$ & $3(10.7)$ \\
\hline
\end{tabular}

high as the delayed effect of displacement of morphine from the $\mu$-opioid receptors followed by the administration of naltrexone took place. If pellets from MS-sNT capsules were crushed, dissolved, solubilized, and then injected, both morphine and naltrexone would be simultaneously injected. It would have been inappropriate to conduct such a study with crushed pellets due to the concern over the presence of excipients such as talc, but future studies of this nature could include simultaneous administration. Additional studies assessing bioavailability and subjective responses to administration of tampered product by routes other than intravenous or oral (e.g. nasal) are also warranted.

This controlled clinical study was conducted in opioid-experienced, non-opioid-dependent men who had not previously used the intravenous route to abuse their drugs. Selection of the study population in human drug-abuse liability studies may impact outcomes and present challenges for which there are few established standards. ${ }^{[12,35,36]}$ Guidance from the Center for Drug Evaluation and Research suggests that subjects in a study should have experience with drugs with psychoactive properties similar to those of the study drug, but do not specify route of administration. ${ }^{[37]}$ National Advisory Council on Drug Abuse guidelines state that the "rationale for exposure to new drugs, to higher doses, or to new routes of administration should be clear and compelling." ${ }^{[38]}$ For example, one may question whether the experience of intravenous administration of an opioid in subjects who had not previously used this route to abuse opioids might encourage future opioid abuse by the intravenous route. Abuse liability studies involving intravenous administration of the study drug have been performed in non-drug-abusing subjects, intravenous-naive subjects, and intravenous-experienced abusers. ${ }^{[34,36,39,40]}$ A small study reported that cocaine use patterns did not change after intravenousnaive subjects participated in a study with investigational intravenous cocaine administration. ${ }^{40]}$ Kaufman, et al. ${ }^{[40]}$ suggested that this outcome was influenced by the fact that the controlled clinical setting in which the intravenous drug was administered during the study was very different from that typically associated with intravenous drug abuse. Overall, the findings from this and other similarly designed trials provide a basis for establishing abuse liability. However, these results are centered on a subset of the population of abusers (i.e. nondependent recreational drug users). Abuse liability may differ in other subsets of drug users such as opioid-dependent individuals who, upon tampering, may be susceptible to naltrexoneprecipitated withdrawal (e.g. patients with chronic pain who misuse or abuse opioids, abusers addicted to opioids, or to new initiates to opioid abuse). A study is underway to determine the effects of the quantity of naltrexone in MS-sNT on opioiddependent individuals. Future studies are needed to address the overall impact that MS-sNT and other formulations designed to reduce attractiveness for abuse will have on misuse, abuse, and diversion in the community. 


\section{Conclusion}

Opioids are effective and important in the treatment of chronic, moderate to severe pain in appropriately selected patients; ${ }^{[41]}$ however, in the current climate of increased illicit use of prescription opioid analgesics, there is a need to address the goal of successfully treating pain while minimizing the risks of abuse. ${ }^{[11]}$ MS-sNT capsules provide analgesia when taken orally as directed but are designed to release naltrexone if they are tampered with by crushing. Results of this intravenous study suggest that the ratio of naltrexone to morphine within MS-sNT capsules is sufficient to decrease the subjective effects of morphine should MS-sNT pellets be tampered with by crushing and solubilized and then injected intravenously in subjects similar to the study population. This feature may reduce the consequent attractiveness of MS-sNT capsules to these abusers. Assessment of the true clinical significance of these findings will require further study.

\section{Acknowledgments}

Lynn Webster, Franklin Johnson, Joseph Stauffer, and Sabrina Ciric were responsible for the study design and analysis. All authors were responsible for analysis and interpretation of data, conception, and writing of the manuscript, and decision to submit the manuscript for publication and approval of the final version.

The authors thank Donald C. Manning, MD, PhD, and Paul F. Cavanaugh Jr, PhD, formerly of Alpharma Pharmaceuticals LLC (Bridgewater, NJ, USA), a wholly owned subsidiary of King Pharmaceuticals Inc., which was acquired by Pfizer Inc. in March 2011, for critical review of the manuscript; Jody M. Cleveland, MS, of Pfizer Inc. (Cary, NC, USA) for statistical review and support; and Brad Bath, $\mathrm{PhD}$, of Lifetree Clinical Research (Salt Lake City, UT, USA) and Tonya Marmon, DrPH, of Synteract Inc. (Carlsbad, CA, USA) for scientific input. Writing and editorial support for this manuscript was provided by Carol Berry, MSc, and Jessica Krauklis, BS, of Quintiles Medical Communications (Parsippany, NJ, USA) in close consultation with the authors and funded by Pfizer Inc.

Lynn R. Webster has received funding from King Pharmaceuticals Inc., which was acquired by Pfizer Inc. in March 2011, for clinical research, consulting, and participation in advisory boards. He has also received funding for clinical research and/or consulting, honoraria, and participation in advisory boards from Adolor Corp.; Alkermes, Inc; Allergen, Inc; American Board of Pain Medicine; Astellas; AstraZeneca; Bayer Healthcare; BioDelivery Systems International; Boston Scientific; Cephalon Inc; Collegium Pharmaceuticals; Covidien;
Covidien Mallinkrodt; Eisai; Elan Pharmaceuticals; Gilead Sciences; GlaxoSmithKline; Janssen Pharmaceutical K.K.; Meagan Medical; Medtronic; Nektar Therapeutics; NeurogesX, Inc; Nevro Corporation; Pharmacofore, Inc.; Purdue Pharma; Shionogi USA. Inc.; St Renatus; SuCampo Pharma Americas, USA; TEVA Pharmaceuticals (Sub-1); Theravance; Theravance, Inc; Vertex; and Xanodyne Pharmaceuticals. Franklin K. Johnson is a former employee of Alpharma Pharmaceuticals LLC, a wholly owned subsidiary of King Pharmaceuticals Inc., which was acquired by Pfizer Inc. in March 2011, and owned stock in Alpharma Pharmaceuticals LLC. He is also a coinventor of EMBEDA ${ }^{\circledR}$ technology. Joseph Stauffer is a former employee of Alpharma Pharmaceuticals LLC, a wholly owned subsidiary of King Pharmaceuticals Inc., which was acquired by Pfizer Inc. in March 2011, and owns stock options and patents for Alpharma Pharmaceuticals LLC. Beatrice Setnik is an employee of Pfizer Inc. and owns company stocks in King Pharmaceuticals Inc. Sabrina Ciric is an employee of Celerion (formerly MDS Pharma Services), which performed the analytical services for this study.

This study was sponsored by Alpharma Pharmaceuticals LLC, a wholly owned subsidiary of King Pharmaceuticals Inc., which was acquired by Pfizer Inc. in March 2011.

\section{References}

1. Sloan P, Babul N. Extended-release opioids for the management of chronic non-malignant pain. Expert Opin Drug Deliv 2006; 3 (4): 489-97

2. Woolf CJ, Hashmi M. Use and abuse of opioid analgesics: potential methods to prevent and deter non-medical consumption of prescription opioids. Curr Opin Investig Drugs 2004; 5 (1): 61-6

3. National Institute on Drug Abuse (NIDA). Prescription medications, NIDA news [online]. Available from URL: http://www.nida.nih.gov/DrugPages/prescription.html [Accessed 2009 Apr 21]

4. Substance Abuse and Mental Health Services Administration. Results from the 2008 National Survey on Drug Use and Health: national findings [online]. Office of Applied Studies, NSDUH Series H-36, HHS publication no. (SMA) 09-4434. Rockville (MD). Available from URL: http:// oas.samhsa.gov [Accessed 2009 Oct 2]

5. Substance Abuse and Mental Health Services Administration. Drug Abuse Warning Network, 2006: national estimates of drug-related emergency department visits [online]. Office of Applied Studies, DAWN Series D-30, DHHS publication no. (SMA) 08-4339. Rockville (MD). Available from URL: http://dawninfo.samhsa.gov [Accessed 2010 Aug 1]

6. Substance Abuse and Mental Health Services Administration. Treatment of episode data set (TEDS) highlights: 2006; national admissions to substance abuse treatment services [online]. Office of Applied Studies, DASIS Series: S-40, DHHS publication no. (SMA) 08-4313. Rockville (MD). Available from URL: http://oas.samhsa.gov [Accessed 2010 Aug 1]

7. Hall AJ, Logan JE, Toblin RL, et al. Patterns of abuse among unintentional pharmaceutical overdose fatalities. JAMA 2008; 300 (22): 2613-20 
8. Johnston LD, O'Malley PM, Bachman JG, et al. Monitoring the future: national results on adolescent drug use; overview of key findings, 2008. Bethesda (MD): National Institute on Drug Abuse, US Department of Health and Human Services, 2009. NIH publication no. 09-7401

9. Wright IV C, Kramer ED, Zalman MA, et al. Risk identification, risk assessment, and risk management of abusable drug formulations. Drug Alcohol Depend 2006; 83 (Suppl. 1): $\mathrm{S} 68-76$

10. Kuehn BM. Opioid prescriptions soar: increase in legitimate use as well as abuse. JAMA 2007; 297 (3): 249-51

11. Katz N. Abuse-deterrent opioid formulations: are they a pipe dream? Curr Rheumatol Rep 2008; 10 (1): 11-8

12. Katz NP, Adams EH, Chilcoat H, et al. Challenges in the development of prescription opioid abuse-deterrent formulations. Clin J Pain 2007; 23 (8): 648-60

13. McColl S, Sellers EM. Research design strategies to evaluate the impact of formulations on abuse liability. Drug Alcohol Depend 2006; 83 (Suppl. 1): S52-62

14. House of Representatives. Making appropriations for Agriculture, Rural Development, Food and Drug Administration, and related agencies programs for the fiscal year ending September 30, 2006, and for other purposes: conference report (to accompany H.R. 2744), 109-255; 109th Congress, 1st Session, 2005

15. Center for Drug Evaluation and Research, FDA, US Department of Health and Human Services (statement of Sandra L Kweder, MD, Deputy Director, Office of New Drugs). Prevention of prescription drug abuse before the Subcommittee on Criminal Justice, Drug Policy and Human Resources House Committee on Government Reform (2006 Jul 26)

16. National Center for Injury Prevention and Control, Centers for Disease Control and Prevention, US Department of Health and Human Services (statement of Leonard J Paulozzi, MD, MPH, medical epidemiologist). Trends in unintentional drug overdose deaths before the Senate Judiciary Subcommittee on Crime and Drugs (2008 Mar 12)

17. Gonzalez JP, Brogden RN. Naltrexone: a review of its pharmacodynamic and pharmacokinetic properties and therapeutic efficacy in the management of opioid dependence. Drugs 1988; 35 (3): 192-213

18. Naltrexone hydrochloride tablets [package insert]. Hazelwood (MO): Mallinckrodt Inc., 2009

19. Vivitrol [package insert]. Frazer (PA): Cephalon Inc., 2007

20. EMBEDA $^{\circledR}$ [package insert]. Bristol (TN): King Pharmaceuticals Inc., June 2009

21. Stauffer J, Setnik B, Sokolowska M, et al. Subjective effects and safety of whole and tampered morphine sulfate and naltrexone hydrochloride (ALO-01) extended-release capsules versus morphine solution and placebo in experienced non-dependent opioid users: a randomized, double-blind, placebo-controlled, crossover study. Clin Drug Investig 2009; 29 (12): 777-90

22. Johnson FK, Stark JG, Bieberdorf FA, et al. Relative oral bioavailability of morphine and naltrexone derived from crushed morphine sulfate and naltrexone hydrochloride extended-release capsules versus intact product and versus naltrexone solution: a single-dose, randomized-sequence, open-label, three-way crossover trial in healthy volunteers. Clin Ther 2010; 32 (6): 1149-64
23. Cole JO, Orzack MH, Beake B, et al. Assessment of the abuse liability of buspirone in recreational sedative users. J Clin Psychiatry 1982; 43 (12 Pt 2): 69-75

24. Cicero TJ, Surratt H, Inciardi JA, et al. Relationship between therapeutic use and abuse of opioid analgesics in rural, suburban, and urban locations in the United States. Pharmacoepidemiol Drug Saf 2007; 16 (8): 827-40

25. International Conference on Harmonisation. ICH Topic E 6 (R1) guideline for good clinical practice [online]. European Medicines Agency. Available from URL: http://www. emea.europa.eu/pdfs/human/ich/013595en.pdf [Accessed 2010 Aug 1]

26. World Medical Association (WMA). WMA Declaration of Helsinki: ethical principles for medical research involving human subjects [online]. Available from URL: http:// www.wma.net/en/30publications/10policies/b3/index.html [Accessed 2011 Jan 5]

27. Jasinski DR. Assessment of the abuse potentiality of morphinelike drugs (methods used in man). In: Martin W R, editor. Drug Addiction. New York (NY): Springer-Verlag, 1977: 197-258

28. Shram MJ, Sathyan G, Khanna S, et al. Evaluation of the abuse potential of extended release hydromorphone versus immediate release hydromorphone. J Clin Psychopharmacol 2010; 30 (1): 25-33

29. Knaggs RD, Crighton IM, Cobby TF, et al. The pupillary effects of intravenous morphine, codeine, and tramadol in volunteers. Anesth Analg 2004; 99 (1): 108-12

30. Benjamini Y, Hochberg Y. Controlling the false discovery rate: a practical and powerful approach to multiple testing. J Royal Stat Soc Series B 1995; 57 (1): 289-300

31. Data on file. Natick (MA): Analgesic Solutions, 2011

32. Ghodse AH, Greaves JL, Lynch D. Evaluation of the opioid addiction test in an out-patient drug dependency unit. $\mathrm{Br}$ J Psychiatry 1999; 175: 158-62

33. Fliegert F, Kurth B, Göhler K. The effects of tramadol on static and dynamic pupillometry in healthy subjects: the relationship between pharmacodynamics, pharmacokinetics and CYP2D6 metaboliser status. Eur J Clin Pharmacol 2005; 61 (4): 257-66

34. Stoops WW, Hatton KW, Lofwall MR, et al. Intravenous oxycodone, hydrocodone, and morphine in recreational opioid users: abuse potential and relative potencies. Psychopharmacology (Berl) 2010; 212 (2): 193-203

35. Balster RL, Bigelow GE. Guidelines and methodological reviews concerning drug abuse liability assessment. Drug Alcohol Depend 2003; 70 (3 Suppl.): S13-40

36. Azolosa JL, Stitzer ML, Greenwald MK. Opioid physical dependence development: effects of single versus repeated morphine pretreatments and of subjects' opioid exposure history. Psychopharmacology (Berl) 1994; 114 (1): 71-80

37. US Department of Health and Human Services, FDA. Guidance for industry: assessment of abuse potential of drugs. Rockville (MD): US Department of Health and Human Services, 2010 [online]. Available from URL: http://www.fda.gov/cder/guidance/index.htm [Accessed 2011Jul 17]

38. National Advisory Council on Drug Abuse (NACDA). NACDA guidelines for administration of drugs to human 
subjects [online]. Available from URL: http://drugabuse. gov/funding/hsguide.html [Accessed 2010 Aug 1]

39. Dershwitz M, Walsh JL, Morishige RJ, et al. Pharmacokinetics and pharmacodynamics of inhaled versus intravenous morphine in healthy volunteers. Anesthesiology 2000; 93 (3): 619-28

40. Kaufman MJ, Levin JM, Kukes TJ, et al. Illicit cocaine use patterns in intravenous-naive cocaine users following investigational intravenous cocaine administration. Drug Alcohol Depend 2000; 58 (1-2): 35-42
41. Chou R, Fanciullo GJ, Fine PG, et al. Clinical guidelines for the use of chronic opioid therapy in chronic noncancer pain. J Pain 2009; 10 (2): 113-30

Correspondence: Lynn R. Webster, MD, Medical Director, Lifetree Clinical Research, and Senior Consultant to Omega Pain Clinic, 3838 South 700 East, Suite 200, Salt Lake City, UT 84106, USA.

E-mail: LRWebsterMD@gmail.com 